(International
http://dergipark.org.tr/ijaws

Araştırma Makalesi

\title{
Samsun ili Çayır ve Meralarında Bitki Çeşitliliğinin Orta Dereceli Tahribat Hipotezine Göre Otlatma ve Erozyon Faktörleri ile Test Edilmesi
}

\author{
Mustafa Sürmen ${ }^{1}$, Tamer Yavuz ${ }^{2}$, Burak Sürmen ${ }^{3 *}$, Ali İmamoğlu ${ }^{4}$ \\ ${ }^{1}$ Aydın Adnan Menderes Üniversitesi, Ziraat Fakültesi, Tarla Bitkileri Bölümü, Aydın \\ ${ }^{2}$ Kırşehir Ahi Evran Üniversitesi, Ziraat Fakültesi, Tarla Bitkileri Bölümü, Kırşehir \\ ${ }^{3}$ Karmanoğlu Mehmetbey Üniversitesi, Kamil Özdağ Fen Fakültesi, Biyoloji Bölümü, Karaman \\ ${ }^{4}$ Nevşehir Hacı Bektaş Veli Üniversitesi, Fen Edebiyat Fakültesi, Biyoloji Bölümü, Nevşehir \\ Geliş tarihi (Received): 25.07.2020 Kabul tarihi (Accepted): 15.09.2020
}

\begin{abstract}
Anahtar kelimeler:
Tahribat, jeoistatistik, bitki çeşitliliği

*Sorumlu yazar

buraksurmen@gmail.com

Özet. Erozyon ve otlatma çayır ve meralarda biyolojik çeşitliliği etkilyen önemli faktörler arasındadır. Tahribat ile biyolojik çeşitlilik arasındaki ilişkinin olumsuz yönde olacağı düşünülse de bazı durumlarda biyoçeşitliliği artııııı etkisi bilinmektedir. Bu durum orta dereceli tahribat hipotezi ile açıklanmaktadır. Bu hipoteze göre tahribatın orta şiddette oldduğu durumlarda biyoçeşitliliğin daha yüksek olacağı savunulmuştur. Bu çalışmada toprak organik madde içeriği yönünden birbirine benzer olan Samsun ilinin çayır ve mera alanlarında yürütülmüştür. Erozyon ve otlatma şiddetine göre oluşturulan grupların bitki çeşitliliği hesaplanmış ve karşılaştırılmıştır. Elde edilen sonuçlara göre bu iki tahribat faktörünün bitki çeşitliliğine etkisi ortaya konmuş ve özellikle otlatma şiddetinin orta dereceli olduğu grupta çeşitlilik indeksleri yüksek bulunmuştur. Erozyon için ise çeşitliliğin en yüksek olduğu grup şiddetli erozyonun gözlemlendiği çayır ve meralar olmuştur. Ayrıca Samsun İli'nde çayır ve mera olarak kullanılan arazilerin tamamını temsil eden alansal dağılım haritaları çizilmiş alanlar hakkında değerlendirmeler ortaya konmuştur.
\end{abstract}

\section{The Testing of Plant Diversity in the Meadows and Pastures of Samsun Province for Grazing and Erosion Factors according to Intermediate Disturbance Hypothesis}

\section{Keywords:}

Disturbance, plant diversity, geostatistical

\begin{abstract}
Erosion and grazing are among the most important factors affecting biodiversity in meadows and pastures. However, although the relationship between disturbance and biodiversity is thought to be negative, in some cases, it is known to increase the biodiversity effect. This situation is explained by the intermediate disturbance hypothesis. According to this hypothesis, it is argued that biodiversity will be higher when the disturbance is moderate. This study was carried out in meadow and pasture areas in Samsun province, which are similar in terms of soil organic matter content. The biological diversity of the groups formed according to the erosion and grazing level were calculated and compared. According to the results obtained, the effect of these two disturbance factors on species diversity was revealed, and the diversity indexes were found to be high especially in the group where grazing intensity was moderate. For erosion, the most severely group was meadows and pastures, where severe erosion was observed. In addition, spatial distribution maps drawn on all of the lands used as meadows and pastures in Samsun Province have been evaluated.
\end{abstract}




\section{GíRiş}

Çayır ve mera alanları dünya üzerinde yaklaşık \%40'lık alanı kaplayan, bitki ve hayvan varlığı açısından önemli işlevleri olan sahalardır (Morrison, 2006). Doğal alanlar olarak kabul edilen bu ekosistemler, birçok çevresel faktör tarafından etkilenmektedir. Çayır ve meralardaki bitki çeşitliliğini etkileyen faktörlerin başında otlatma ve erozyon gelmektedir. Bunların yanında taşılık, toprak derinliği ve toprak organik madde içeriği de bitki çeşitliliğini etkileyen önemli faktörlerdendir (Biswas ve Mallik, 2011)

Erozyon, suyun ve rüzgârın etkisiyle gerçekleşen doğal jeolojik bir süreçtir. Bu doğal sürecin meralar üzerindeki olumsuz etkisi birçok çalışmada ortaya konmuştur (Ren ve ark., 2012; Gamoun, 2014). Altın ve ark. (2005) bitki örtüsünün toprağı kaplama oranı azaldıkça erozyon şiddetinin arttığını ortaya koymuştur. Çayır ve meraların maruz kaldığı bir diğer olumsuz faktör ise aşırı otlatmadır. Aşırı otlatma, otlatmaya karşı dirençli ve yem değeri olmayan türlerin çoğalmasına, besin değeri yüksek bitkilerin ise uzaklaşmasına neden olmaktadır (Sürmen ve Kara, 2018; Sürmen, ve ark., 2015; Türk ve ark., 2015). Yine birçok çalışmada otlatma şiddetinin toprağın fiziksel ve kimyasal özellikleriyle beraber bitki örtüsünün floristik yapısında da değişikliklere neden olduğu ortaya konmuştur (Sun ve Liddle, 1993; Amiri ve ark., 2008). Bunun yanı sıra otlatmanın neden olduğu bitki örtüsünün çiğnenme veya ezilme durumu otsu bitki topluluklarının bozulmsına neden olmaktadır (Grime, 1973; Liddle, 1991; Kobayashi ve ark., 1997). Taşlılık, erozyon, jeolojik formasyon ve toprak özelliklerinden kaynaklanan bir durumdur (Imamoglu ve Dengiz, 2017). Taşlılı̆ın yüksek olması çayır ve meralardaki botanik kompozisyonunun zayıflamasına dolayısıyla mera sağlık durumunun zayıflamasına neden olmaktadır (Ünal ve ark., 2012).

Connell (1979) tahribat ile bitki çeşitliliği arasındaki ilişkiyi değerlendirirken, orta derecedeki tahribatın tür çeşitliliğini en üst seviyeye çıkardığını öne sürmüştür (Lázaro ve ark., 2016). Bu durumu düşük ve yüksek tahribatta türler arasındaki rekabetin yoğun olmasına bağlayarak, her iki durumun tür zenginliğini azalttığını belirtmiştir (Eldridge ve ark., 2016; Fedrigo ve ark., 2018). Ayrıca orta dereceli tahribatın türler arasındaki rekabeti düşürmesinin yanıııra abiyotik faktörlerin sınırlayıcı etkilerini azaltması veya ortadan kaldırmasından dolayı çevresel stres faktörlerinin oluşturduğu etkileri azaltmasıyla da ür çeşitliliğini arttırdığı tahmin edilmektedir (Li ve Shipley, 2019). Bu görüş ampirik ve teorik çalışmalar ile desteklenmiş (Lázaro ve ark., 2016; Connell, 1979; Pollock ve ark., 1998) ve çeşitli araştırmalar ile bitki türlerinin zenginliğinin tahribat dereceleri boyunca arttığı veya azaldığı ortaya konmuştur (Tilman, 1983; Martinsen ve ark., 1990; Wilson ve Tilman, 1991; Collins ve Glenn, 1997; Yuan ve ark., 2016; Fedrigo ve ark., 2018). Tahribatın orta dereceli olduğu habiatlarda ise bitki çeşitliliğinin yüksek olduğu bulunmuştur (Flöder ve Sommer, 1999; Buckling ve ark., 2000; Pueyo ve ark., 2006; Eldridge ve ark., 2016).

Ekologlar için tür çeşitliliğinin belirlenmesi, komünite ekolojisinin köşe taşlarınından biri olarak kabul edilmektedir (Biswas ve Mallik, 2011). Tür çeşitlliği ve ekosistem işlevleri arasında tahribatın ilişkisi ise çevresel değişkenlerle açıklanabilir (Shea ve ark., 2004). Ayrıca çevresel değişkenler habitat devamlılığını etkilemekte ve belirli bir tahbribata karşı türlerin habitat duyarlıığına adapte olduğu belirlenmiştir. Böylece çeşitlilik, tahribat ve ekosistem fonksiyonları arasındaki ilişkinin belirllenmesinde doğrudan öneme sahip olur (Biswas ve Mallik, 2010)

Çayır ve meralar biyotik ve abiyotik tahribatların ortaya çıkıtğı alanlar olduğu düşünüldüğünde, meydana gelen çevresel değişimlerin tür çeşitliliğini etkileyeceği kaçınılmazdır. Tahribat ile biyolojik çeşitlilik arasındaki ilişkiyi açıklayan görüşlere bakıldığında; orta dereceli tahribatın tür çeşitliliğini arttırdığı birçok çalışmada ortaya konmuştur (Dupré ve Diekmann, 2001; McIntyre ve ark., 2003; Yuan ve ark., 2016; Fedrigo ve ark., 2018). Bu çalışmada çayır ve mera alanlarındaki önemli tahribat faktörleri olan otlatma ve erozyonun biyolojik çeşitliliğe olan etkisi araştııımıştır.

\section{MATERYAL VE METOT}

\section{Çalışma Alanı}

Araştırma sahası Samsun il sınırları içerisinde yer alan çayır ve mera arazileridir. İlin çayır ve mera varlığı toplam 16.683 ha'dır (Şekil 1). Samsun İli iklim özellikleri bakımından kıyıda ve iç kesimde farklııı gösterir. llıman iklim özellikleri görülen kıyı bölümünde yazlar sıcak, kışlar ılık ve yağışı, iç bölgede ise yükselti ve karasallık etkisine bağlı olarak yazlar serin, kışlar soğuk yağmur ve kar yağışlı geçmektedir. Samsun meteoroloji istasyonu verilerine göre yıllık yağış miktarı 706.3 mm olduğu, en çok yağışın ise Kasım $(83.8 \mathrm{~mm})$ ayında düştüğü görülmektedir. Ilin yıllık sıcaklık ortalaması ise $14.5^{\circ} \mathrm{C}$ dir. Ortalama en soğuk ay Şubat $\left(7.1^{\circ} \mathrm{C}\right)$, ortalama en sıcak ay ise Ağustos ayıdır $\left(23.5^{\circ} \mathrm{C}\right)$. 


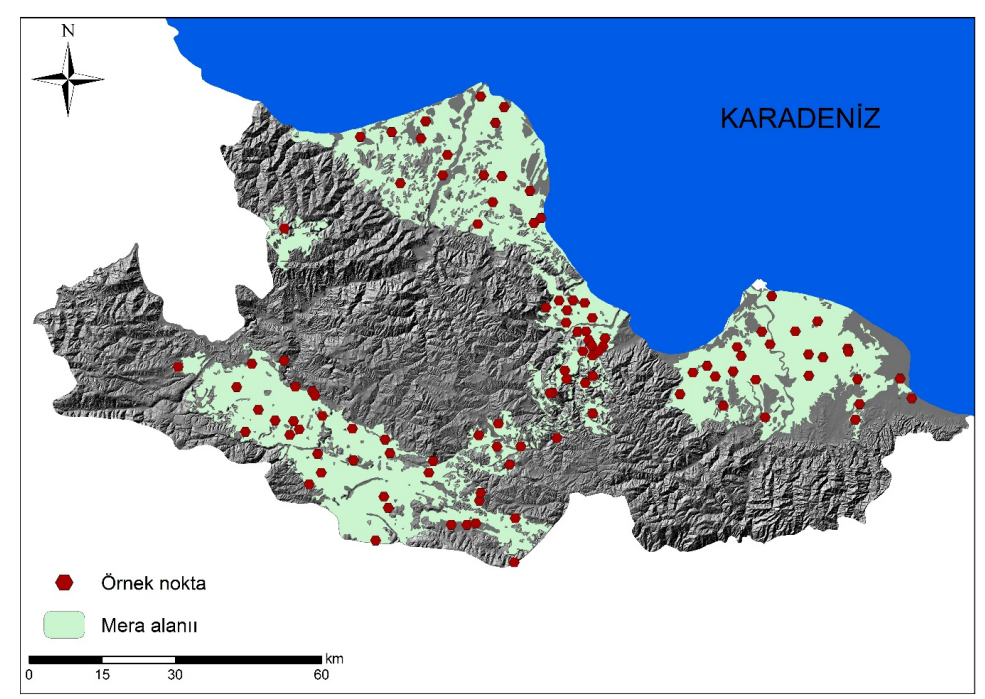

Şekil 1. Çalışılan çayır ve meralar.

Figure 1. Meadow and pastures were studied.

Çalışmanın amacına uygun olacak şekilde Samsun ili'nin tümünü kapsayacak şekilde toplam 106 çayır ve merada vejetasyon örnekleri alınmıştır (Şekil 1). Arazi çalışmaları hâkim bitkilerin çiçeklendiği dönemde ve her bir çayır mera için doğu, batı, kuzey ve güney yöneyleri esas alınarak bitki türlerinin yoğunlukları modifiye edilmiş tekerlekli lup yöntemi ile tespit edilmiştir (Koç ve Çakal 2004).

\section{Tahribat Faktörlerin Belirlenmesi}

Çalışmanın amacı için iki tahribat faktörü (erozyon ve otlatma baskısı) belirlenmiştir. Erozyon ve otlatma baskısına göre belirlenen grupların organik madde miktarı yönünden birbirine benzer olmasına özen gösterilmiştir. Böylece toprak organik madde içeriğinin biyolojik çeşitlilik üzerine olan etkisi en aza indirgenmiştir. Erozyon dereceleri arazi gözlemleri ve il envanter bilgileriyle, otlatma şiddeti ise arazi çalışmalarında gözlemlenen mera toprağındaki sıkışma durumu ve mera vejetasyonlarında bulunan bitki türlerine göre değerlendirilmiştir. Elden edilen sonuçlar mera amenajman ve ıslah çalışmalarında kullanılan standart yöntemlere göre sınıflandırılmıştır (Çizelge 1) (Anonim, 2005).

Çizelge 1. Çevresel özelliklerin sınıflandırma değerleri.

Table 1. Classification values of enviromental features.

\begin{tabular}{ccc}
\hline Sınıflandırma değeri & Erozyon derecesi $\left(\right.$ ton $\mathbf{~ h a}^{-1}$ ) & Otlatma \\
\hline 1 & Çok hafif $<2$ & Yok \\
2 & $2<$ Hafif $<5$ & Hafif \\
3 & $5<$ Orta $<10$ & Orta \\
4 & $10<$ Yüksek $<50$ & Yoğun \\
5 & $50<$ Şiddetli $<100$ & Çok yoğun \\
6 & $100<$ Çok şiddetli $<500$ & - \\
\hline
\end{tabular}

\section{Biyoçeşitlilik Hesaplamaları}

Biyolojik çeşitliliğin hesaplanmasında tür zenginliği (species richness) ve türlerin yoğunluğu (species evenness) yöntemlerinden yararlanılmıştır. Bunun için yaygın olarak kullanılan alfa $(\alpha)$ ve beta $(\beta)$ çeşitlilik indeksleri tercih edilmiştir. $\alpha$ çeşitlilik indeksi komünitelerdeki tür çeşitliliğini ortaya koyar (Gülsoy ve Özkan, 2008; Kılınç ve ark., 2006) ve bu çalışmada çayır ve meralarda yaygın olarak kullanılan Shannon-Wienner indeksleri tercih edilmiştir.

Shannon-Wienner çeşitlilik indeksi türlerin yüzde bolluklarını oransal bir şekilde standardize ettiği için daha çok kullanılmaktadır. Shannon-Wienner çeşitlilik indeksi $(H)$ aşağıdaki formülle (1) hesaplanır ve indeks değerleri 0 ile 5 arasında değişir.

$$
H=\sum_{i=1}^{S} p i x \ln p i
$$

H: Shannon-Wienner'in çeşitlilik indeksi; s: komünitedeki toplam tür sayısı (H/richness); Pi: i türüne ait tüm bireylerin oranı; In: sayının doğal logaritması 
Sürmen ve ark., Samsun İli Çayır ve Meralarında Bitki Çeşitliliğinin Orta Dereceli Tahribat Hipotezine göre Otlatma ve Erozyon Faktörleriye Test Edilmesi

Shannon-Weiner çeşitlilik indeksine göre türlerin yoğunluğu (J/evenness) aşağıdaki formülle (2) ile hesaplanır:

$$
J=\left(-\sum_{i=1}^{S} p i x \operatorname{lnpi}\right) / \ln s
$$

Bu formülde $s$, tür sayısını; pi, i türünün yüzde örtüş değerinin bütün türlerin yüzde örtüş değerlerinin toplamına oranını; In, doğal logaritmayı ifade etmektedir. Evenness 0-1 arasında bir değer alır ve 1 değeri tam evenness değerini ifade eder. Shannon-Weiner $(J)$ değeri ne kadar yüksekse bu bölgede bulunan türlerin birey sayısı diğer komünitelere göre birbirine daha yakındır (Kılınç ve ark., 2006).

$\beta$ çeşitlilik indeksi bölgeler veya kommüniteler arasındaki tür çeşitliliğindeki farklılıktır. Beta diversity çok farklı bölgeler veya çevreler arasındaki tür kompozisyonundaki farklılıkları ve bu habitatların değişme hızını ortaya koyar. Beta diversity habitatlar arasındaki çeşitlilik modellerini ifade eder ve türlerin adapte olabilme yetenekleri ve gelişim ihtiyaçlarına göre değişim oranlarını gösterir. Yüksek beta diversity değerleri çevresel gradiyentin bir fonksiyonu olarak tür sayısında yüksek orandaki değişimin göstergesidir (Kılınç ve ark., 2006). Whittaker"a göre beta ( $\beta$ ) çeşitlilik aşağıda verilen formülle (3) hesaplanır;

$$
\beta=S / \alpha-1
$$

$\beta$; beta çeşitlilik, S; toplam tür sayısı; $\alpha$, ortalama tür zenginliği (Gülsoy ve Özkan, 2008) ifade eder.

Hesaplamalar BioDiversity Pro (McAleece ve ark., 1997) programıyla yapılmıştır.

\section{istatistiksel Analizler}

Tahribat (erozyon ve otlatma) faktörlerine göre belirlenen gruplar dikkate alınarak istatististiksel analizler yapılmıştır. Illk olarak bu iki faktöre göre oluşturulan gruplar arasında organik madde yönünden istatistiksel farklılık olup olmadığı tek yönlü varyans analizi ile belirlenmiştir. Her faktör için belirlenen gruplar arasında biyoçeşitlilik değerlerinin istatistiksel farklıı̆̆ tek yönlü varyans analizi kullanılarak belirlenmiştir. Ayrıca gruplar arasındaki farklıı̆ı̆ın tespiti için Tukey çoklu karşılaştırma tesit kullanılmıştır. Tahribat ve çevresel faktörlerin biyoçeşitlilik değerleriyle olan iliş̧isi Pearson korelasyon testi kullanılarak belirlenmiştir. İstatistiksel analizler SPSS 20 programı ile yapılmıştır (Corp, 2013).

\section{Jeoistatistiksel Analizler}

Biyoçeşitlilik verilerine (Shannon-Wienner indeksine göre tür zenginliği $(H)$ ve türlerin yoğunluğu $(J)$, beta $(\beta)$ çeşitlilik indeksi) ve tahribat (erozyon ve otlatma) faktörlerine ait alansal dağılım haritaları çizilmiştir. Harita çizimleri vejetasyon ve çevresel parametrelere ait semivariyogram değerlerinin hesaplaması sonrası, en çok kullanılan IDW, RBF ve Kriging yöntemlerinden doğal (ordinary), evrensel (universal), basit (simple) kriging enterpolasyon hesaplamaları kullanıımıştır. Yöntemlere ait enterpolasyon hesaplamalarının karşılaştııımalarında ölçülen değerler ve tahmin edilen değerler arasındaki ilişkiyi sorgulayabilmek, ölçülen değerlere en yakın sonucu veren başka bir ifade ile yöntemler arasından en uygun olanının seçebilmek için literatürde farklı karşılaştırma yöntemlerinin dikkate alındığı görülmektedir (Imamoglu ve Dengiz, 2017). Analizler için kullanılan indekslerin hesaplanması ve alan içerisinde bu indekslerin dağılımlarının belirlenmesi amacıyla ArcGIS 10.2v jeoistatistiksel modellerinden yararlanılmıştır (İmamoğlu ve ark., 2016). Bu çalışmada birden çok yöntem kullanılarak harita çizimi için en uygun olanı hata kareler ortalamasının karekökü (RMSE) değerlerine (4) göre belirlenmiştir. Çünkü en düşük RMSE değerini veren yöntem en uygun yöntemdir (Arslan, 2012). Bu çalışma için biyoçeşitlilik, tahribat ve çevresel özelliklere ait RMSE değerleri incelenmiş ve en düşük RMSE değerlerine sahip yöntemler haritaların çizimi için seçilmiştir (Çizelge 2).

$$
R M S E=\sqrt{\frac{\sum\left(z_{i *}-z_{i}\right)^{2}}{n}}
$$

Eşitlikte; $Z_{i}$ : tahmin edilen değer, $Z_{i^{*}}$ ölçülen değer ve $n$ örnek sayısını ifade etmektedir (Arslan, 2012). 
Sürmen ve ark., Samsun İli Çayır ve Meralarında Bitki Çeşitliliğinin Orta Dereceli Tahribat Hipotezine göre Otlatma ve Erozyon Faktörleriye Test Edilmesi

Çizelge 2. Araştırılan parametrelere uygulanan jeoistatistiksel yöntemler.

Table 2. Geostatistical methods were applied to studied parameters.

\begin{tabular}{|c|c|c|c|c|c|c|c|c|}
\hline \multirow{2}{*}{\multicolumn{2}{|c|}{$\begin{array}{c}\text { Enterpolasyon } \\
\text { Models }\end{array}$}} & \multirow[b]{2}{*}{ Pover Semivariogram } & \multicolumn{6}{|c|}{ RMSE } \\
\hline & & & \multirow{2}{*}{$\begin{array}{l}\begin{array}{l}\text { Plant } \\
\text { cover }\end{array} \\
11,47\end{array}$} & \multirow{2}{*}{$\begin{array}{c}\mathbf{H} \\
0.559\end{array}$} & \multirow{2}{*}{$\begin{array}{c}\text { J } \\
0.01685\end{array}$} & \multirow{2}{*}{$\frac{\boldsymbol{\beta}}{3.528}$} & \multirow{2}{*}{$\begin{array}{c}\text { Erosion } \\
0.898\end{array}$} & \multirow{2}{*}{$\begin{array}{c}\text { Grazing } \\
1.030\end{array}$} \\
\hline & & 1 & & & & & & \\
\hline \multirow{2}{*}{\multicolumn{2}{|c|}{ IDW }} & 2 & 12,65 & 0.590 & 0.01757 & 3.844 & 0.958 & 1.081 \\
\hline & & 3 & 13,98 & 0.622 & 0.01757 & 4.170 & 1.018 & 1.164 \\
\hline \multirow{2}{*}{\multicolumn{2}{|c|}{ RBF }} & Completely Regularized Spline & 12,01 & 0.147 & 0.01699 & 3.604 & 0.912 & 1.029 \\
\hline & & Thin Plate Spline & 18,41 & 0.206 & 0.02387 & 5.123 & 1.207 & 1.366 \\
\hline \multirow{9}{*}{ Kriging } & \multirow{3}{*}{ OK } & Spherical & 12,98 & 0.147 & 0.01665 & 3.493 & 0.886 & 1.119 \\
\hline & & Exponential & 13,24 & 0.148 & 0.01677 & 3.522 & 0.886 & 1.110 \\
\hline & & Gaussian & 12,39 & 0.146 & 0.01667 & 3.423 & 0.889 & 1.133 \\
\hline & \multirow{3}{*}{ SK } & Spherical & 12,89 & 0.147 & 0.01664 & 3.489 & 0.882 & 1.059 \\
\hline & & Exponential & 13,17 & 0.148 & 0.01666 & 3.521 & 0.883 & 1.058 \\
\hline & & Gaussian & 12,33 & 0.147 & 0.01677 & 3.428 & 0.881 & 1.075 \\
\hline & \multirow{3}{*}{ UK } & Spherical & 11,96 & 0.147 & 0.01661 & 3.538 & 0.886 & 1.119 \\
\hline & & Exponential & 12,10 & 0.148 & 0.01666 & 3.639 & 0.886 & 1.110 \\
\hline & & Gaussian & 11,59 & 0.147 & 0.01663 & 3.418 & 0.887 & 1.133 \\
\hline
\end{tabular}

\section{BULGULAR}

Erozyon ve otlatma derecelerine göre belirlenen çayır ve mera gruplarının organik madde içeriği birbirine benzerdir. Çizelge 3 incelendiğinde, belirlenen grupların organik madde yönünden farklı olmadığı istatistiksel olarak ortaya konmuştur.

Çizelge 3. Organik madde yönünden erozyon ve otlatma faktörlerine göre belirlenen grupların tek yönlü varyans analizi sonuçları.

Table 3. One-way analysis of variance results of the groups determined according to erosion and grazing factors in terms of organic matter.

\begin{tabular}{|c|c|c|c|c|c|c|}
\hline & & Kareler toplamı & $\begin{array}{c}\text { Serbestlik } \\
\text { derecesi }\end{array}$ & Ortalama kare & F değeri & P değeri \\
\hline & Gruplar arası & 36.418 & 4 & 9.105 & 2.898 & $0.26 n s$ \\
\hline \multirow[t]{3}{*}{ Erozyon } & Gruplar içi & 317.339 & 101 & 3.142 & & \\
\hline & Toplam & 353.758 & 105 & & & \\
\hline & Gruplar arası & 15.130 & 4 & 3.782 & 1.128 & $0.35 n s$ \\
\hline \multirow[t]{2}{*}{ Otlatma } & Gruplar içi & 338.628 & 101 & 3.353 & & \\
\hline & Toplam & 353.758 & 105 & & & \\
\hline
\end{tabular}

Erozyon ve otlatma derecesine göre beş grubta sınıflandırılmışır, Erozyon derecelerine göre çayır ve meraların \% 61.32'sinde hafif ve çok hahif erozyon görülürken, \% 16.98'inde ise yüksek ve şiddetli erozyon görülmektedir. Otlatma şiddetine göre çayır ve meraların \% 60.38'inde yoğun ve çok yoğun otlatma görülmektedir (Çizelge 4).

Çizelge 4. Belirlenen grupların erozyon ve otlatma özellikleri

Table 4. Erosion and grazing features of determined groups

\begin{tabular}{lcccccc}
\hline \multicolumn{7}{c}{ Erozyon derecesi } \\
\hline & Çok hafif & Hafif & Orta & Yüksek & Şiddetli & Toplam \\
\hline Çayır ve mera sayısı & $9(\% 8.49)$ & $56(\% 52.83)$ & $23(\% 21.70)$ & $14(\% 13.21)$ & $4(\% 3.77)$ & $106(\% 100)$ \\
\hline \multicolumn{7}{c}{ Otlatma şiddeti } \\
\hline Çayır ve mera sayısı & Yok & Hafif & Orta & Yoğun & Çok yoğun & \\
\hline
\end{tabular}


Sürmen ve ark., Samsun İli Çayır ve Meralarında Bitki Çeşitliliğinin Orta Dereceli Tahribat Hipotezine göre Otlatma ve Erozyon Faktörleriye Test Edilmesi

Alansal dağılım haritaları incelendiğinde; otlatmanın hemen hemen meraların tamamında etkili olduğu görülmektedir. Erozyon derecesine bakıldığında; Yeşilırmak deltasının doğusu ile Kızılırmak Deltasının batısındaki belirli bir alanda erozyonun çok hafif olduğu, geri kalan çayır ve meralarda ise hafif ve orta derecede olduğu bulunmuştur (Şekil 2).
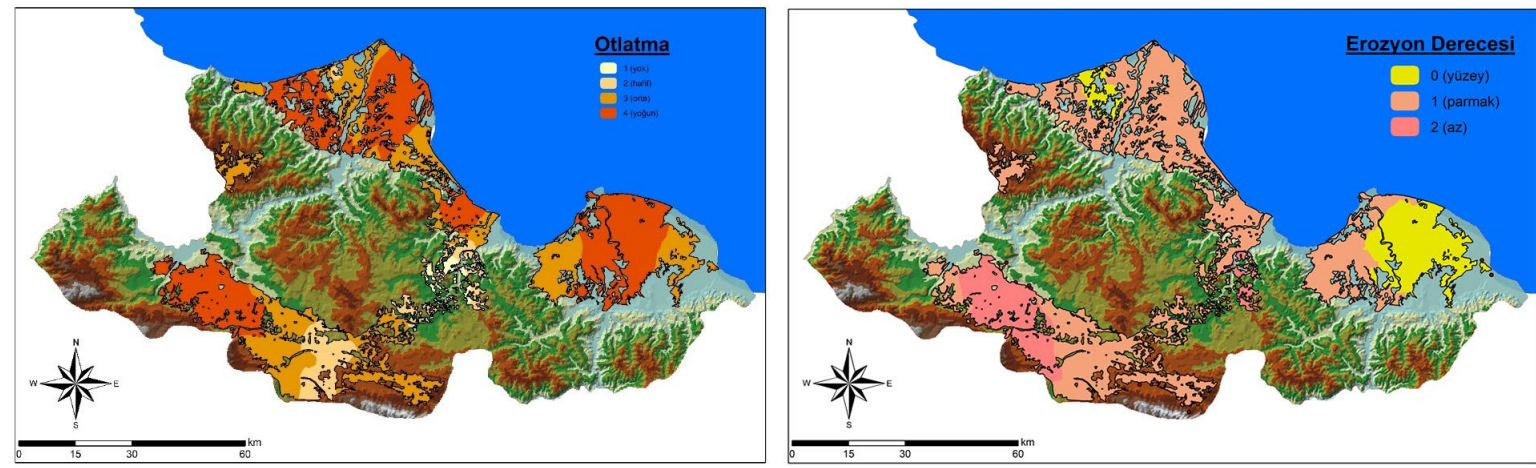

Şekil 2. Çayır ve meralara ait otatma ve erozyon yoğunluk haritaları.

Figure 2. Density maps of meadow and pastures belonging to erosion and grazing.

Çayır ve meraların bitki ile kaplılıkları incelendiğinde \%74.79-95.71 arasında değiştiği tespit edilmiştir. Jeoistatistiksel sonuçlara göre bitki kapalılığının alansal dağılım haritası incelendiğinde çayır ve meraların çoğunluğunun yüksek kapalılık oranlarına sahip olduğu görülmektedir (Şekil 3).

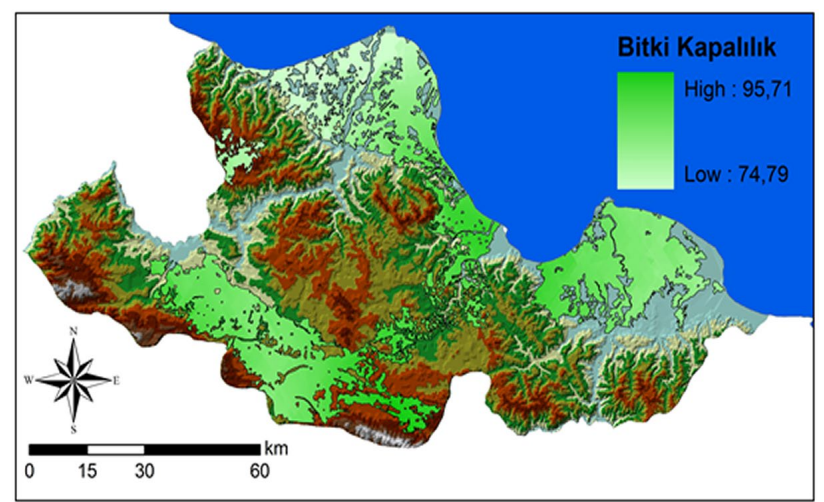

Şekil 3. Çayır ve meralara ait bitki kaplılığı haritası.

Figure 3. Plant cover maps of meadow and pastures.

Tahribat faktörlerine göre sınıflandıılan çayır ve meraların tür sayıları incelendiğinde; 10 ile 40 arasında değiştiği tespit edilmiştir. Erozyon derecelerine göre ortalama ve en yüksek tür sayısı yüksek erozyonun görüldüğü çayır ve meralarda tespit edilmiştir. Ortalama tür sayısının em düşük olduğu çayır meralar ise şiddetli erozyonun görüldüğü yerlerde hesaplanmıştır. Otlatma şiddetinin orta düzeyde olduğu alanların tür sayısına bakıldığında; 40 farklı türün bulunduğu tespit edilmiştir. Otlatma şiddetinin çok yoğun olduğu alanlarda ise ortalam tür sayısı 16 olarak hesaplanmıştır (Şekil 4).
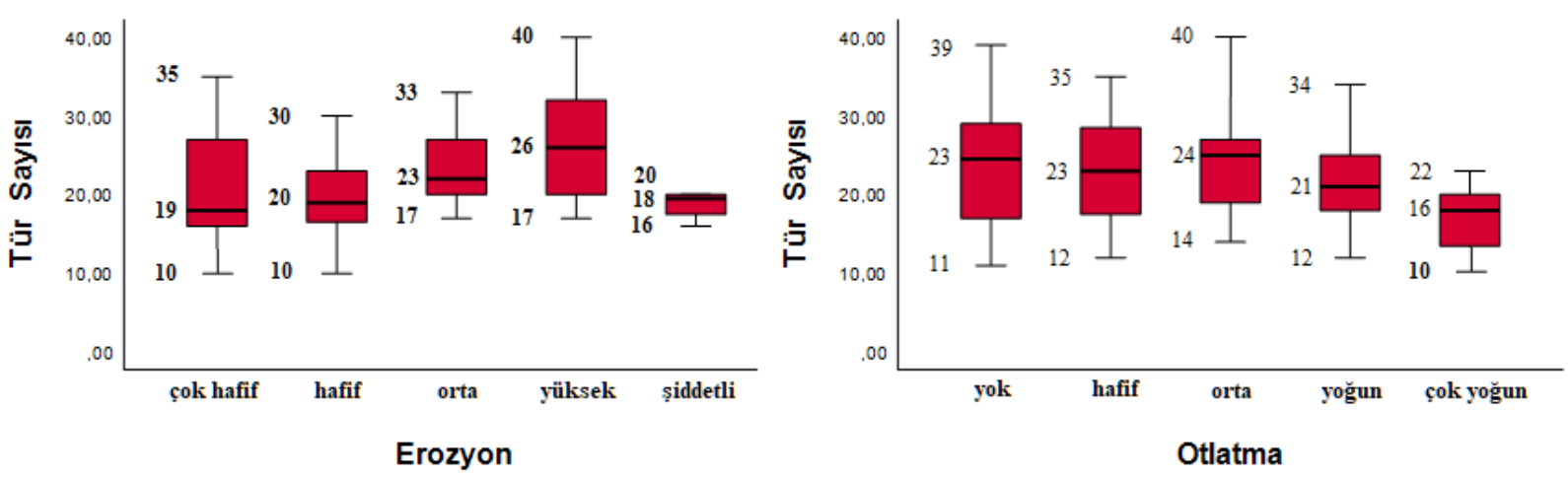

Şekil 4. Erozyon ve otlatma gruplarında tespit edilen en az, an çok ve ortalama tür sayıları.

Figure 4. Minimum, maximum and average species number of grazing and erosion groups. 
Tahribat faktörlerine göre belirlenen gruplarda bitki türlerinin kalite dereceleri incelendiğinde; azalıcı, çoğalıcı ve istilacı türlerin farklı yoğunluklara sahip olduğu bulunmuştur. Erozyon şiddeti arttıkça istilacı tür yoğunluğunun arttığı, azalııı ve çoğalıcı türlerin yoğunluğunun ise azaldığı görülmüştür. Otlatma şiddeti arttıkça istilacı türlerin yoğunluğunun azaldığı, çoğalıcı türlerin ise arttığı görülmüştür. Azalıcı türlerin ise dalgalı bir seyir islediği, en yüksek yoğunluğa otlatmanın hafif olduğu alanlarda, en düşük yoğunluğa ise çok yoğun otlatmanın görüldüğü çayır ve meralarda tespit edilmiştir (Şekil 5).
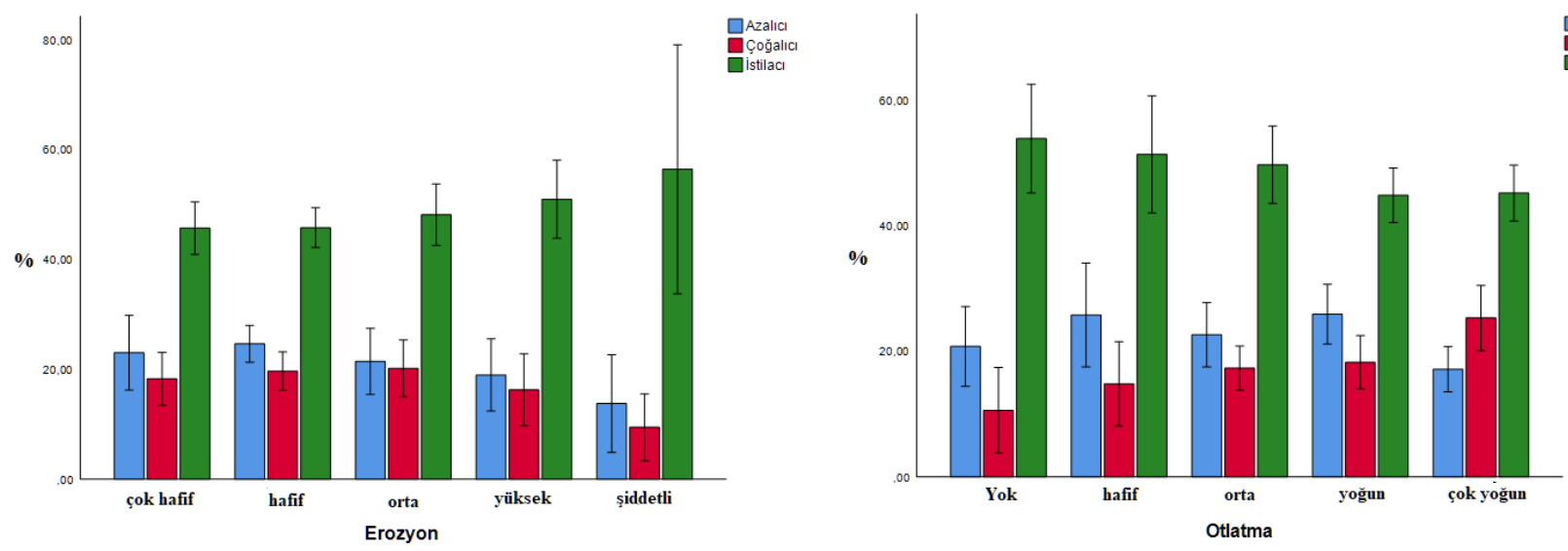

Şekil 5. Erozyon ve otlatma gruplarında azalıcı, çoğalıcı ve istilacı tür yoğunlukları.

Figure 5. Densities of decreaser, increaser and invader species in erosion and grazing goups.

Çayır ve mera gruplarının biyoçeşitlilik verileri Shannon-Wienner'a göre tür çeşitliliği (H/richness), tür yoğunluğu (J/evennes) ve Whittaker'a göre beta $(\beta)$ indeksleri hesaplanmıştır. Erozyon gruplarına göre biyoçeşitlilik verileri incelendiğinde; tür çeşitliliği (H/richness) ve beta çeşitliliği sonuçlarının istatistiksel olarak $(p<0.05)$ farklı olduğu bulunmuştur. Tür yoğunluğu (J/evennes) sonuçlarının erozyon grupları arasında istatistiksel farklılık bulunmamıştır. Otlatma gruplarına göre biyoçeşitlilik sonuçları incelendiğinde; tür çeşitliliği $(H /$ richness) çeşitliliği sonuçlarının istatistiksel olarak $(p<0.05)$ farklı olduğu, tür yoğunluğu $(J / e v e n n e s)$ ve beta çeşitliliği sonuçlarının ise otlatma grupları arasında istatistiksel olarak farklı olmadığı bulunmuştur (Çizelge 5).

Çizelge 5. Erozyon ve otlatma grupları arasında tür çeşitliliği $(H)$, tür yoğunluğu $(J)$ ve beta $(\beta)$ indeksleri arasındaki tek yönlü varyans analizi (Harfler $\mathrm{p}<0.05$ düzeyinde Tukey HSD testi sonuçlarını ifade eder.).

Table 5. One-way analysis of variance between the species diversity $(H)$, species density $(J)$ and beta $(\beta)$ indices between erosion and grazing groups (Small letters represent Tukey HSD test results at $p<0.05$ level).

\begin{tabular}{|c|c|c|c|c|c|c|}
\hline & \multicolumn{5}{|c|}{ Erozon derecesi } & \multirow{2}{*}{$p$ value } \\
\hline & Çok hafif & Hafif & Orta & Yüksek & Şiddetli & \\
\hline $\mathrm{H}$ indeks & $1.133 \mathbf{b}$ & $1.201 \mathbf{b}$ & $1.260 \mathrm{ab}$ & $1.326 \mathbf{a}$ & $1.206 \mathbf{b}$ & $0.041^{*}$ \\
\hline $\mathrm{J}$ indeks & $0.952 a$ & $0.960 \mathbf{a}$ & $0.957 a$ & $0.960 \mathbf{a}$ & $0.966 \mathbf{a}$ & $0.064 n s$ \\
\hline$\beta$ indeks & $3.257 \mathrm{bc}$ & $8.002 \mathbf{a}$ & $6.328 \mathbf{a b}$ & $4.711 \mathrm{abc}$ & $1.559 c$ & $0.000 * *$ \\
\hline \multicolumn{7}{|c|}{ Otlatma şiddeti } \\
\hline & Yok & Hafif & Orta & Yoğun & Çok yoğun & \\
\hline $\mathrm{H}$ indeks & $1.274 a$ & $1.261 \mathrm{a}$ & $1.295 a$ & $1.248 \mathrm{ab}$ & $1.105 \mathbf{b}$ & $0.000 * *$ \\
\hline $\mathrm{J}$ indeks & $0.965 a$ & $0.958 \mathbf{a}$ & $0.962 \mathbf{a}$ & $0.957 \mathbf{a}$ & $0.956 \mathbf{a}$ & $0.513 n s$ \\
\hline$\beta$ indeks & $5.979 a$ & $6.387 \mathbf{a}$ & $5.279 a$ & $6.285 a$ & $8.222 \mathbf{a}$ & $0.059 \mathrm{~ns}$ \\
\hline
\end{tabular}

Biyoçeşitlilik sonuçlarının alansal dağılımına bakıldığında; erzoyon derecesinin orta ve yüksek olduğu çayır meralarda tür çeşitliliği (H/richness) yüksek bulunmuştur. Tür yoğunluğu (J/evennes) değerlerine bakıldığında erozyon gruplarının birbirine yakın değerlerde olduğu görülmektedir. Bununla beraber beta çeşitliliği sonuçlarının hafif erozyon görülen grupta en yüksek, erozyonun şiddetli görüldüğü grupta ise en düşük olduğu tespit edilmiştir. Otlatma yoğunluğuna göre biyçeşitlilik verilerinin dağılımı incelendiğinde orta şiddetli otlatmanın görüldüğü çayır ve meralarda tür çeşitliliği (H/richness) ve tür yoğunluğu (J/evennes) değerlerinin yüksek olduğu hesaplanmıştır. Otlatmanın çok yoğun olduğu çayır ve meralarda ise beta çeşitliliği çok yüsek, tür çeşitliliği (H/richness) ve tür yoğunluğu (J/evennes) değerleir ise en düşük olarak hesaplanmıştır (Şekil 6). 

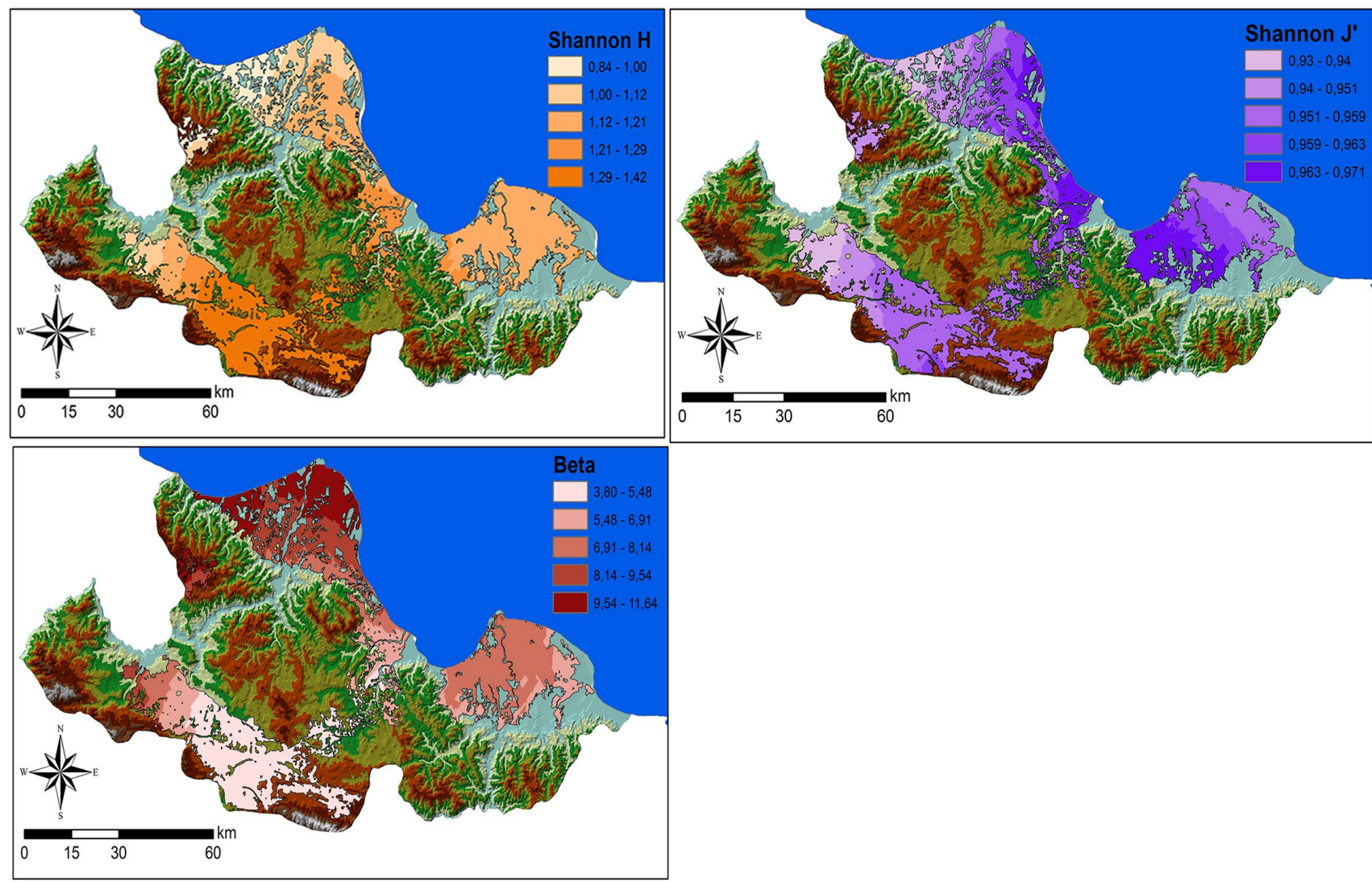

Şekil 6. Çayır ve meralara ait tür çeşitliliği $(H)$, tür yoğunluğu $(J)$ ve beta $(\beta)$ indekslerine göre yoğunluk haritaları. Figure 6. Density maps of meadows and pastures according to species diversity $(H)$, species density $(J)$ and beta $(\beta)$ indices.

Son olarak tahribat faktörleri ile biyoçeşitlilik ve türlere ait özellikler arasında yapılan korelasyon sonuçları incelendiğinde; Erozyonun tür çeşitliliği (H/richness), tür sayısı ve istilacı tür sayısı ile pozitif ilişkili olduğu bulunurken, Beta çeşitlilik ile negatif ilişkili olduğu bulunmuştur. Otlatma faktörü ile yapılan korelasyonlar incelendiğinde ise beta ve çoğalıcı bitkiler ile pozitif ilişkili olduğu, tür çeşitliliği (H/richness), tür sayısı ve istilacı tür sayısı ile negatif ilişkili olduğu belirlenmiştir (Çizelge 6).

Çizelge 6. Erozyon ve otlatma derecelerinin biyoçeşitlilik ve türlere ait özellikler ile yapılan korelasyon sonuçları. Table 6. Correlation results of erosion and grazing degrees with biodiversity and species features.

\begin{tabular}{cccccccc}
\hline & $\mathbf{H}$ & $\mathbf{J}$ & Beta & Tür sayısı & Azalıcı & Çoğalıcı & İstilacı \\
\hline Erozyon & $0.249^{*}$ & 0.074 & $-0.240^{*}$ & $0.238^{*}$ & -0.159 & -0.121 & $0.217^{*}$ \\
Otlatma & $-0.319^{* *}$ & -0.146 & $0.200^{*}$ & $-0.333^{* *}$ & -0.126 & $0.320^{* *}$ & $-0.238^{*}$ \\
\hline
\end{tabular}

\section{TARTIŞMA}

Çayır ve meralarda aşıı otlatmanın zemin florasına zarar verdiği, aynı zamanda baskın türlerin yenilenmesini engellediği bilinmektedir (Malik ve ark., 2016). Bu çalışmada inceleme yapılan çayır ve meraların \% 60'ında yoğun ve çok yoğun otlatma tespit edilmiş olup, bu alanlarda tür sayısının daha düşük olduğu bulunmuştur. Ayrıca aşırı otlatmanın çalı ve ağaç türlerinin olumsuz etkilediği dolayısıyla tür zenginliğini azalttığı ortaya konmuştur (Roder ve ark., 2002; Kumar ve Shahabuddin, 2005). Bununla birlikte (Pettit ve ark., 1995) aşırı otlatmanın tür zenginliği ve çeşitlliğini azalttığını ve ilgisiz türlerin oranını arttırdığını belirtmiştir. Elde edilen sonuçlar ile birlikte değerIndirildiğinde yoğun ve aşırı yoğun otlatılan çayır ve meralarda biyoçeşitlilik indekslerinin ( $\alpha$ çeşitlilik indeksleri) daha düşük olduğu hesaplanmıştır (Faria ve ark., 2018). Ayrıca otlatma şiddetinin aşırı olduğu çayır ve meralarda $\beta$ indeksinin yüksek olması, tahribatın yoğun olduğunu göstermektedir. Farklı otlatma derecelerine sahip çayır ve meralardaki bu farklılık özellikle tür zenginliği açısından istatistiksel olarakta bulunmuştur. Bunun yanında otlatma şiddetinin artışıla birlikte istilacı ve çoğalıcı türlerin değiştiği görülmüştür. Önceki çalışmalarda da vejetasyonda meydana gelen değişikliklerin önemli bir nedeninin otlatma şiddeti olduğu belirlenmiştir (Zhao ve ark., 2007; García ve ark., 2009; Tälle ve ark., 2016). 
Sonuçlara dayanarak otlatma şiddetinin tür zenginliği ve çeşitliliği üzerinde önemli derecede etkili olduğunu özellikle otlatmanın yoğun olduğu çayır ve meralarda tür sayısının ve çeşitlilik indekslerinin daha düşük olduğunu, fakat otlatma şiddetinin orta seviyede olduğu çayır veralarda ise tür sayısının ve çeşitliğinin daha yüksek olduğunu söyleyebiliriz. Lu ve ark. (2017) otlak ekosistemlerinde çeşitli derecelerdeki otlatmanın tür zenginliğini etkilediğini ortaya koyması bu çalışmadaki değişkenliği de açıklamaktadır. Bu nedenle genel olarak otlatmanın orta derece de olduğu alanların yüksek biyoçeşitliliğe sahip olacağını söyleyebiliriz (Tälle ve ark., 2016).

Otlatma şiddetine göre çizilen alansal dağılım haritaları incelendiğinde; otlatmanın aşırı olduğu alanlarda yüzeyin bitki ile kaplılık oranının ve $\alpha$ çeşitlilik indekslerinin daha düşük olduğunu, $\beta$ indeksinin ise daha yüksek olduğu bulunmuştur. Önceki çalışmalar, ya bitki örtüsünün (Pohl ve ark., 2009; Martin ve ark., 2010) ya da çayırların (Callaway ve ark., 2000; Wiesmair ve ark., 2017) bozulmuş olması otlak çeşitliliğine ilişkin etkilerini bağımsız olarak araştırmıştır. Bitki toplulukları ve ekosistemler bir dereceye kadar otlatmanın neden olduğu tahribatı tolere edebilir, ancak tipik olarak tahribat mevcut eşikleri aşarsa kararsız hale gelebilirler (Westoby ve ark., 2002; Zhu ve ark., 2008; Villnäs ve ark., 2013).

Bir diğer tahribat faktörümüz olan erozyonun çayır ve meralardaki durumu incelendiğinde; alanların çoğunda erozyon şiddetinin hafif olduğu bulunmuştur. Özellikle Yeşiırmak Deltası'nın doğusu ile Kızılırmak Deltası'nın batısında erozyonun çok hafif olması bu alanların toprak yapısının bozulmamış ve rüzgâr erozyonunun etkisi altında kalmamasından kaynaklandığını söyleyebiliriz (Öztürk vd., 2015). Bitki çeşitliliği ile erozyan arasındaki ilişki incelendiğinde; en yüksek tür sayısına sahip alanların orta ve yüksek erozyonun görüldüğü çayır ve meralar olduğu tespit edilmiştir. Özellikle erozyon derecesinin çok yüksek olduğu çayır ve meralarda ortalama tür sayısının çok düşük olduğu bulunmuştur. Türlerin kalite derecelerine göre, erozyonun şiddetli olduğu alanlarda istilacı türlerin yoğunluklarının arttığı bulunmuştur. Bitki örtüsü ile toprak erozyonu arasındaki bu güçlü ilişki daha önceki çalışmalarda ortaya konmuştur (Linse ve ark., 2006; Peratoner ve Pötsch, 2019). Dağlık alanlarda eroyonun daha şiddetli olması ile birlikte nispeten biyoçeşitliliğin daha düşük olduğu bulunmuş ve düşük tür çeşitliliğinin erozyonun oluşumunu hızlandıran doğal bir süreç olduğu tespit edilmiştir (Wiesmair ve ark., 2017). Elde edilen sonuçlara bakıldığında; erozyon şiddeti arttıkça çayır ve meralardaki tür kalitesinin değiştiği özellikle istilacı tür yoğunluğunun arttığı gözlemlenmiştir. Bununla birlikte erozyon grupları arasındaki biyoçeşitlilik indeksleri incelendiğinde $\mathrm{H}$ (richness) ve $\beta$ indeksinin istatistiksel olarak farklıdır.

Erozyonu azaltmak, genellikle bitki biyoçeşitliliği ile yakından ilişkili olup, bitki tür zenginliğinin erozyon oranlarını düşürdüğü, bununla beraber düşük tür zenginliğinin ise erozyonun doğal sürecini hızlandırdığı belirlenmiştir (Allen ve ark., 2016). Artan kök biyokütlesinin topraklara stabilite sağladığı ve bu nedenle "toprak erozyonunu önlemenin biyolojik çeşitliliğin artırılması önerilmiştir (Balvanera ve ark., 2006; Liu ve ark., 2017).

Tahribat faktörleri ile yapılan korelasyonlar incelendiğinde; otlatma şiddetinin tahribatı arttırdığını beta biyoçeşitliliğide azalttığı belirlenirken, erozyonun tür çeşitliliği ile pozitif ilişkili olduğu belirlenmiştir.

Bu sonuç genellikle, orta düzeyde rahatsızığın toplumun art arda ilerlemesinde ve topluluk yapısının ve tür çeşitliliğinin korunmasında önemli bir rol oynayabileceğini gösteren ara rahatsızlık hipotezi ile tutarlıdır (Grime, 1973; Duru ve ark., 2010; Kiełtyk ve Mirek, 2015).

\section{SONUÇ}

Çayır ve meralarda önemli tahtribat faktörleri olan erozyon ve otlatmanın biyolojik çeşitliliği üzerindeki etkisi orta dereceli tahribat hipotezine göre incelenmiş ve otlamanın orta dereceli olduğu alanlarda yüksek, aşırı otlatmanın olduğu anlanlarda daha düşük biyolojik çeşitliliğin olduğu tespit edilmiştir. Erozyon için ise biyolojik çeşitliliğin çok hafif erozyon görülen alanlardan yüksek erozyon görülen alanlara doğru arttığı fakat şiddetli erozyonun görüldüğü çayır ve meralarda ise yeniden biyolojik çeşitliliğin azaldığı bulunmuştur. Ayrıca Samsun Ili'nde çayır ve mera olarak kullanılan arazilerin tahribat faktörleri, biyolojik çeşitlilik değerleri ve bazı vejetasyon özellikleri ile ilgili bilgiler çizilen alansal dağılım haritaları ile gösterilmiştir. Nispeten her iki faktör için orta dereceli tahribat hipotezini desteklediğini söyleyebiliriz. Özellikle otlatma ile ilgili elde ettiğimiz sonuçların daha önceki çalışmalarda elde edilen sonuçlar ile daha uyumlu olduğu görülmektedir (Ren ve ark., 2012; Gamoun, 2014; Eldridge ve ark., 2016; Fedrigo ve ark., 2018). Sonuç olarak erozyon şiddetinin belli bir seviyeye kadar biyolojik çeşitlilik açııından tolere edilebildiği fakat otlatma baskısının belli bir derecede tutulmasının uygun olduğu bulunmuştur.

\section{ÇIKAR ÇATIŞMASI}

Yazarlar arasında herhangi bir çıkar çatışması yoktur. 


\section{YAZAR KATKISI}

Mustafa Sürmen, Tamer Yavuz ve Burak Sürmen çalışmanın planlanması, arazi çalışmaları ve makale yazımında katkılar sağlarken, Ali İmamoğlu jeoistatistiksel analizlerin uygulanmasında katkı sağlamıştır.

\section{TEŞEKKÜR}

Bu çalışma Türkiye Bilimsel ve Teknolojik Araştırma Kurumu (TÜBiTAK) tarafından $106 \mathrm{G} 017$ numaralı proje ile desteklenmiştir.

\section{KAYNAKLAR}

Allen, D. C., Cardinale, B. J., \& Wynn-Thompson, T. (2016). Plant biodiversity effects in reducing fluvial erosion are limited to low species richness. Ecology, 97(1), 17-24.

Altın, M., Tuna, C., Nizam, İ., \& Ateş, E. (2005). Pirinççi köyü meraları dolgu alanlarını bitkilendirme uygulamaları. VI. Tarla Bitkileri Kongresi, Antalya.

Amiri, F., Ariapour, A., \& Fadai, S. (2008). Effects of livestock grazing on vegetation composition and soil moisture properties in grazed and non-grazed range site. Journal of Biological Sciences, 8(8), 1289-1297.

Anonim. (2005). Toprak ve arazi sınıflaması standartları teknik talimatı. http://www. tarim.gov.tr/Belgeler /Mevzuat/ Talimatlar/ Toprak Arazi Siniflamasi Standartlari Teknik TalimativellgiliMevzuat_yeni.pdf. Erişim tarihi: 21 Mayıs 2020.

Arslan, H. (2012). Spatial and temporal mapping of groundwater salinity using ordinary kriging and indicator kriging: The case of Bafra Plain, Turkey. Agricultural Water Management, 113, 57-63.

Balvanera, P., Pfisterer, A. B., Buchmann, N., He, J. S., Nakashizuka, T., Raffaelli, D., \& Schmid, B. (2006). Quantifying the evidence for biodiversity effects on ecosystem functioning and services. Ecology Letters, 9(10), 1146-1156.

Biswas, S. R., \& Mallik, A. U. (2010). Disturbance effects on species diversity and functional diversity in riparian and upland plant communities. Ecology, 91(1), 28-35.

Biswas, S. R., \& Mallik, A. U. (2011). Species diversity and functional diversity relationship varies with disturbance intensity. Ecosphere, 2(4), art52.

Buckling, A., Kassen, R., Bell, G., \& Rainey, P. B. (2000). Disturbance and diversity in experimental microcosms. Nature, 408(6815), 961-964.

Callaway, R. M., Kikvidze, Z., \& Kikodze, D. (2000). Facilitation by unpalatable weeds may conserve plant diversity in overgrazed meadows in the Caucasus Mountains. Oikos, 89(2), 275-282.

Collins, S. L., \& Glenn, S. M. (1997). Intermediate disturbance and its relationship to within- and between-patch dynamics. New Zealand Journal of Ecology, 21(1), 103-110.

Connell, J. H. (1979). Intermediate-disturbance hypothesis. Science, 204(4399), 1345-1345.

Corp, I. (2013). IBM SPSS statistics for windows. Armonk, NY.

Dupré, C., \& Diekmann, M. (2001). Differences in species richness and life-history traits between grazed and abandoned grasslands in southern Sweden. Ecography, 24(3), 275-286.

Duru, M., Ansquer, P., Jouany, C., Theau, J. P., \& Cruz, P. (2010). Comparison of methods for assessing the impact of different disturbances and nutrient conditions upon functional characteristics of grassland communities. Annals of Botany, 106(5), 823-831.

Eldridge, D.J., Poore, A. G. B., Ruiz-Colmenero, M., Letnic, M., \& Soliveres, S. (2016). Ecosystem structure, function, and composition in rangelands are negatively affected by livestock grazing. Ecological Applications, 26(4), 1273-1283.

Faria, N., Peco, B., \& Carmona, C. P. (2018). Effects of haying on vegetation communities, taxonomic diversity and sward properties in mediterranean dry grasslands: A preliminary assessment. Agriculture, Ecosystems \& Environment, 251, 4858.

Fedrigo, J. K., Ataide, P. F., Filho, J. A., Oliveira, L. V., Jaurena, M., Laca, E. A., ... Nabinger, C. (2018). Temporary grazing exclusion promotes rapid recovery of species richness and productivity in a long-term overgrazed Campos grassland. Restoration Ecology, 26(4), 677685.

Flöder, S., \& Sommer, U. (1999). Diversity in planktonic communities: An experimental test of the intermediate disturbance hypothesis. Limnology and Oceanography, 44(4), 1114-1119. 
Sürmen ve ark., Samsun İli Çayır ve Meralarında Bitki Çeşitliliğinin Orta Dereceli Tahribat Hipotezine göre Otlatma ve Erozyon Faktörleriye Test Edilmesi

Gamoun, M. (2014). Grazing intensity effects on the vegetation in desert rangelands of Southern Tunisia. Journal of Arid Land, 6(3), 324-333.

García, R. R., Jáureguı, B. M., García, U., Osoro, K., \& Celaya, R. (2009). Effects of livestock breed and grazing pressure on ground-dwelling arthropods in Cantabrian heathlands. Ecological Entomology, 34(4), 466-475.

Grime, J. P. (1973). Competitive exclusion in herbaceous vegetation. Nature, 242(5396), 344-347.

Gülsoy, S., \& Özkan, K. (2008). Tür çeşitliliğinin ekolojik açıdan önemi ve kullanılan bazı indisler. Süleyman Demirel Üniversitesi Orman Fakültesi Dergisi, 9(1), 168-178.

İmamoğlu, A., Bahadır, M., \& Dengiz, O. (2016). Çorum Alaca havzasında toprak erozyon duyarlılık faktörünün farklı enterpolasyon modeller kullanılarak konumsal dağılımlarının belirlenmesi. Toprak Su Dergisi, 5(1), 8-15.

Imamoglu, A., \& Dengiz, O. (2017). Determination of soil erosion risk using RUSLE model and soil organic carbon loss in Alaca catchment (Central Black Sea region, Turkey). Rendiconti Lincei, 28(1), 11-23.

Kiełtyk, P., \& Mirek, Z. (2015). Importance of molehill disturbances for invasion by Bunias orientalis in meadows and pastures. Acta Oecologica, 64, 29-34.

Kılınç, M., Kutbay, H. G., Yalçın, E., \& Bilgin, A. (2006). Bitki Ekolojisi ve Bitki Sosyolojisi Uygulamaları. Palme Yayınevi, Ankara.

Kobayashi, T., Hori, Y., \& Nomoto, N. (1997). Effects of trampling and vegetation removal on species diversity and microenvironment under different shade conditions. Journal of Vegetation Science, 8(6), 873-880.

Koç, A., \& Çakal, Ş. (2004). Comparison of some rangeland canopy coverage methods. International Soil Congress Natural Resource Management for Sustainable Development, Erzurum.

Kumar, R., \& Shahabuddın, G. (2005). Effects of biomass extraction on vegetation structure, diversity and composition of forests in Sariska Tiger Reserve, India. Environmental Conservation, 32(3), 248-259.

Lázaro, A., Tscheulın, T., Devalez, J., Nakas, G., \& Petanıdou, T. (2016). Effects of grazing intensity on pollinator abundance and diversity, and on pollination services. Ecological Entomology, 41(4), 400-412.

Li, Y., \& Shipley, B. (2019). Functional niche occupation and species richness in herbaceous plant communities along experimental gradients of stress and disturbance. Annals of Botany, 124(5), 861-867.

Liddle, M. J. (1991). Recreation ecology: Effects of trampling on plants and corals. Trends in Ecology \& Evolution, 6(1), 13-17.

Linse, S. J., Mergen, D. E., Smith, J. L., \& Trlica, M. J. (2006). Upland erosion under a simulated most damaging storm. Journal of Range Management, 54(4), 356-361.

Liu, Y., Wu, G., Ding, L., Tian, F., \& Shi, Z. (2017). Diversity-productivity trade-off during converting cropland to perennial grassland in the semi-arid areas of China. Land Degradation \& Development, 28(2), 699-707.

Lu, X., Kelsey, K. C., Yan, Y., Sun, J., Wang, X., Cheng, G., \& Neff, J. C. (2017). Effects of grazing on ecosystem structure and function of alpine grasslands in Qinghai-Tibetan Plateau: a synthesis. Ecosphere, 8(1), e01656.

Malik, Z. A., Pandey, R., \& Bhatt, A. B. (2016). Anthropogenic disturbances and their impact on vegetation in Western Himalaya, India. Journal of Mountain Science, 13(1), 69-82.

Martin, C., Pohl, M., Alewell, C., Körner, C., \& Rixen, C. (2010). Interrill erosion at disturbed alpine sites: Effects of plant functional diversity and vegetation cover. Basic and Applied Ecology, 11(7), 619-626.

Martinsen, G. D., Cushman, J. H., \& Whitham, T. G. (1990). Impact of pocket gopher disturbance on plant species diversity in a shortgrass prairie community. Oecologia, 83(1), 132-138.

McAleece, N., Lambshead, P., Paterson, G., \& Gage, J. (1997). BioDiversity Professional: London.

Mcintyre, S., Heard, K. M., \& Martin, T. G. (2003). The relative importance of cattle grazing in subtropical grasslands: does it reduce or enhance plant biodiversity? Journal of Applied Ecology, 40(3), 445-457.

Morrison, J. (2006). Grasslands of the World. Experimental Agriculture, 42(2), 254-255.

Özturk, D., Beyazit, I., \& Kilic, F. (2015). Spatiotemporal analysis of shoreline changes of the Kizilirmak Delta. Journal of Coastal Research, 31(6), 1389-1402.

Peratoner, G., \& Pötsch, E. M. (2019). Methods to describe the botanical composition of vegetation in grassland research. Die Bodenkultur: Journal of Land Management, Food and Environment, 70(1), 1-18.

Pettit, N. E., Froend, R. H., \& Ladd, P. G. (1995). Grazing in remnant woodland vegetation: changes in species composition and life form groups. Journal of Vegetation Science, 6(1), 121-130.

Pohl, M., Alig, D., Körner, C., \& Rixen, C. (2009). Higher plant diversity enhances soil stability in disturbed alpine ecosystems. Plant and Soil, 324(1-2), 91-102. 
Sürmen ve ark., Samsun İli Çayır ve Meralarında Bitki Çeşitliliğinin Orta Dereceli Tahribat Hipotezine göre Otlatma ve Erozyon Faktörleriye Test Edilmesi

Pollock, M. M., Naiman, R. J., \& Hanley, T. A. (1998). Plant species richness in riparian wetlands-a test of biodiversity theory. Ecology, 79(1), 94

Pueyo, Y., Alados, C. L., \& Ferrer-Benimeli, C. (2006). Is the analysis of plant community structure better than common species-diversity indices for assessing the effects of livestock grazing on a Mediterranean arid ecosystem? Journal of Arid Environments, 64(4), 698-712.

Ren, H., Schönbach, P., Wan, H., Gierus, M., \& Taube, F. (2012). Effects of grazing intensity and environmental factors on species composition and diversity in typical steppe of inner Mongolia, China. PLoS ONE, 7(12), e52180.

Roder, W., Gratzer, G., \& Wangdi, K. (2002). Cattle grazing in the conifer forests of Bhutan. Mountain Research and Development, 22(4), 1-7.

Shea, K., Roxburgh, S. H., \& Rauschert, E. S. J. (2004). Moving from pattern to process: coexistence mechanisms under intermediate disturbance regimes. Ecology Letters, 7(6), 491-508.

Sun, D., \& Liddle, M. J. (1993). A survey of trampling effects on vegetation and soil in eight tropical and subtropical sites. Environmental Management, 17(4), 497-510.

Sürmen, M., \& Kara, E. (2018). Aydın İli ekolojik koşullarında farklı eğimlerdeki mera vejetasyonlarının verim ve kalite özellikleri. Derim, 35(1), 67-72.

Sürmen, M., Yavuz, T., Sürmen, B., \& Kutbay, H. G. (2015). Determination of the population densities of invasive species in meadows and pastures of Samsun. Türkiye Herboloji Dergisi, 18(3), 9-10.

Tälle, M., Deák, B., Poschlod, P., Valkó, O., Westerberg, L., \& Milberg, P. (2016). Grazing vs. mowing: A meta-analysis of biodiversity benefits for grassland management. Agriculture, Ecosystems \& Environment, 222, 200-212.

Tilman, D. (1983). Plant succession and gopher disturbance along an experimental gradient. Oecologia, 60(3), 285-292.

Türk, M., Albayrak, S., \& Bozkurt, Y. (2015). Otlatmanın Farklı yapay meralarda botanik kompozisyon üzerine etkisi. SDÜ Ziraat Fakültesi Dergisi, 10(1), 17-34.

Ünal, S., Mutlu, Z., Mermer, A., Urla, Ö., Ünal, E., Özaydın, K. A., ... Aslan, S. (2012). Çankırı ili meralarının mera durumu ve sağlığının belirlenmesi üzerine bir çalışma. Tarım Bilimleri Araştırma Dergisi, 5(2), 131-135.

Villnäs, A., Norkko, J., Hietanen, S., Josefson, A. B., Lukkari, K., \& Norkko, A. (2013). The role of recurrent disturbances for ecosystem multifunctionality. Ecology, 94(10), 2275-2287.

Westoby, M., Falster, D. S., Moles, A. T., Vesk, P. A., \& Wright, I. J. (2002). Plant ecological strategies: Some leading dimensions of variation between species. Annual Review of Ecology and Systematics, 33(1), 125-159.

Wiesmair, M., Otte, A., \& Waldhardt, R. (2017). Relationships between plant diversity, vegetation cover, and site conditions: implications for grassland conservation in the Greater Caucasus. Biodiversity and Conservation, 26(2), $273-291$.

Wilson, S. D., \& Tilman, D. (1991). Interactive effects of fertilization and disturbance on community structure and resource availability in an old-field plant community. Oecologia, 88(1), 61-71.

Yuan, Z. Y., Jiao, F., Li, Y. H., \& Kallenbach, R. L. (2016). Anthropogenic disturbances are key to maintaining the biodiversity of grasslands. Scientific Reports, 6(1), 22132.

Zhao, W. Y., Li, J. L., \& Qi, J. G. (2007). Changes in vegetation diversity and structure in response to heavy grazing pressure in the northern Tianshan Mountains, China. Journal of Arid Environments, 68(3), 465-479.

Zhu, Z.-H., Lundholm, J., Li, Y., \& Wang, X. (2008). Response of Polygonum viviparum species and community level to longterm livestock grazing in alpine shrub meadow in Qinghai-Tibet Plateau. Journal of Integrative Plant Biology, 50(6), 659672. 